\section{Microarray to be used as routine clinical screen}

The Netherlands Cancer Institute in Amsterdam is to become the first institution in the world to use microarray techniques for the routine prognostic screening of cancer patients. Aiming for a June 2003 start date, the center will use a panoply of 70 genes to assess the tumor profile of breast cancer patients and to determine which women will receive adjuvant treatment after surgery.

Adjuvant therapies

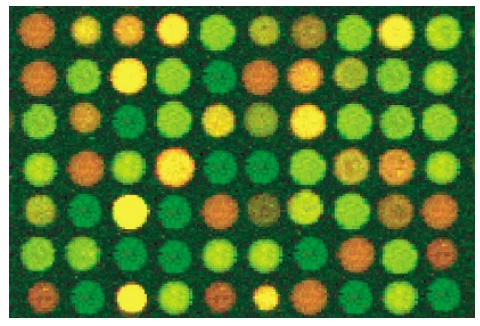

A good prognostic signature

(see News \& Views page 16). "There are at present many women that are overtreated by chemotherapy that based on [microarray] criteria actually have a good profile..." says Van't Veer.

David Botstein, a Stanford researcher who is also developing microarray signatures for breast cancer, foresees that the burgeoning data from the various microarray studies will eventually become include chemo-therapy, hormonal therapy (typically tamoxifen) and sometimes radiation therapy. Over $80 \%$ of breast cancer patients in the US and Europe currently receive adjuvant therapy, and a fraction of the women who do not receive adjuvant therapy suffer tumor recurrences. However, these costly treatments are ridden with side efweight gain, mild memory loss and fatigue.

Presently, standardized prognostic criteria are used to determine who will benefit from adjuvant therapy. These criteria rely on indicators such as histology, biochemical markers of invasive growth, and the presence or absence of hormone receptors and cancerous lymph nodes. But these conventional indicators can give the misleading impression of a non-aggressive tumor-or, alternatively, lead to overtreatment. The Dutch institute, which is affiliated with the 200-bed Antoni van Leeuwenhoek hospital, will use microarray profile analysis in conjunction with conventional prognostic tests. The institute treats around 1,000 breast cancer patients each year, 400 of whom undergo surgery and would have tissue samples available for microarray analysis.

Laura Van't Veer, a researcher at the institute, helped develop the microarray test for the hospital. She notes that the approach could reduce the number of women receiving adjuvant therapy by as much as $35 \%$ while allowing fewer women with high-risk tumors to slip through. These estimates are based on retrospective studies testing the approach in banks of tumors, the most recent of which was published last month in the New England Journal of Medicine brand-name drugs. possibility. riod. billion every year." fects such as premature menopause, await confirmation of the microarray signatures by an independent analysis, says Sjoerd Rondenhuis, an author on the NEJM study.

The Dutch microarray tests are also planned for use in numerous clinical trials. For example, the European Organization for Research and Treatment of Cancer is finalizing plans for a large-scale trial to test the prognostic value of microarrays on lymphnode-negative patients. Patients will receive adjuvant treatment based on their microarray signature. Their outcomes will be compared with patients evaluated solely according to conventional European criteria, called St. Gallen criteria. In other trials of novel treatments, researchers will give patients a microarray test and then later determine how patients with certain profiles responded, says Van't Veer.

Charlotte M. Schubert, New York

\section{Drug costs threaten patent protection}

News that prescription medicines have become the fastest-growing sector of healthcare outlay in the US will add strength to proposals by the Bush Administration to ease regulations on generic production of brand-name drugs. According to a survey released in December by Mercer Human Resource Consulting, the cost of American healthcare rose by $15 \%$ last year, the largest increase since 1990. Individuals paid an average of $\$ 10$ for generic drugs and $\$ 35$ for

The previous month, US Secretary of Health and Human Services Tommy Thompson announced plans to eliminate legislation that allows pharmaceutical companies to invoke a 30-month delay on generic copies being produced. This rule gave innovator drug companies the chance to protect their patent rights in court. However, companies have frequently invoked multiple 30-month delays, indefinitely delaying approval of generic drugs. Thompson's new rule would end that

Around $40 \%$ of drugs currently sold are generic copies. Between now and 2006, patents are set to expire on four times as many drugs as normal during that time period, making them susceptible to copying without even a 30 -month delay pe-

As Nature Medicine went to press, the Pharmaceutical Research and Manufacturers Association (PhRMA), which represents much of the pharmaceutical industry in the US, was expected to lodge its opposition to removal of the 30 month rule. PhRMA's view is that allowing faster access to cheaper generics discourages drug makers from investing huge sums into the research and development of new and potentially breakthrough compounds.

PhRMA claims its members spent more than $\$ 30$ billion in 2001 discovering and developing new medicines, and should be allowed to reap the profits from those investments. For example, the patent on Merck \& Co.'s successful osteoporosis drug Fosomax was recently challenged by two generic drug makers, Teva and Ivax Pharmaceuticals. The court ruled that Merck's patent on the drug, which generated \$455 million in sales last quarter, was valid until August 2007.

But Thompson insists that the change "would bring relief from the high prices that American consumers frequently pay for prescription drugs." Citing his own dollar figures, he predicts that the rule "could save consumers approximately $\$ 3.5$

Marlene Cimons, Washington, D.C. 